Max-Planck-Institut für demografische Forschung

Max Planck Institute for Demographic Research

Konrad-Zuse-Strasse 1 - D-18057 Rostock - GERMANY

Tel +49 (0) 3812081 - 0; Fax +49 (0) 3812081 - 202;

http://www.demogr.mpg.de

MPIDR WORKING PAPER WP 2015-001

MAY 2015

\title{
Spatial Variation in Non-Marital \\ Fertility across Europe: \\ Recent Trends, Past Path Dependencies, and Potential Future Pathways
}

Sebastian Klüsener (kluesener@demogr.mpg.de)

This working paper has been approved for release by: Vladimir Shkolnikov (shkolnikov@demogr.mpg.de), Head of the Laboratory of Demographic Data.

(C) Copyright is held by the authors.

Working papers of the Max Planck Institute for Demographic Research receive only limited review. Views or opinions expressed in working papers are attributable to the authors and do not necessarily reflect those of the Institute. 
Spatial Variation in Non-Marital Fertility across Europe:

Recent Trends, Past Path Dependencies, and Potential Future Pathways

Sebastian Klüsener, Max Planck Institute for Demographic Research 


\begin{abstract}
This article investigates spatiotemporal variation of non-marital fertility across Europe over the last 100 years. In the first 50 years of this period, non-marital fertility was generally declining, reaching very low levels in the mid- $20^{\text {th }}$ century. This was followed by dramatic increases starting in the 1960s. The main aim of this paper is to investigate to what degree historical path dependencies might be relevant for understanding spatial aspects of the recent rise. A secondary aim it so explore prospects for future spatial non-marital fertility variation between and within countries. To investigate historic path dependencies, spatial variation patterns in 1910, 1960, 1975, 1990, and 2007 are compared. The outcomes support the view that historical pattern are relevant for understanding current non-marital fertility variation in most parts of Europe. However, the persistence of the past varies spatially, and seems to fade over time. In terms of future spatial variation between countries, the analysis suggests that an eastwest dichotomy is currently emerging as particularly non-EU member countries with Orthodox Christian or Muslim traditions exhibit higher propensities to remain at or return to comparatively low levels. Within Northwestern Europe, suburban belts around big cities appear to emerge as the last strongholds of marital fertility.
\end{abstract}

Keywords: Persistence of the past, Spatial analysis, Europe, Births outside marriage 


\section{Introduction $^{1}$}

A present-day observer might be astounded by the significance the topic of births outside marriage has been-and is still being-given by researchers and statistical offices (Laslett, 1980; Kiernan, 2004; Kok, 2009; Perelli-Harris et al., 2010). In many European countries, non-marital births have become the norm, with more than $50 \%$ of all new-born children being born to non-married women. This was, however, very different in the Golden Age of Marriage just 50 years ago, during which a non-marital birth was a rare event associated with a range of potentially negative social and legal implications for the new-born child. Today, most non-married mothers are in a stable relationship (Perelli-Harris et al., 2012), and have the option to get married prior to childbirth. Thus, the recent increase in non-marital fertility seems to reflect the reality that the social norm that marriage should precede childbirth, a norm to which past populations have given considerable importance (Laslett, 1980), has far less relevance for current populations. However, studies which have looked at the present degree of spatial variation in non-marital fertility across Europe have found substantial variation mostly between but also in part within countries (Klüsener et al., 2013). Whereas in Northern Europe marital childbearing has become the exception, especially for first births (Lappegård et al., 2014); there are still countries in Southeastern Europe, such as Greece or Albania, where a non-marital childbirth is still a rather rare event.

The results of existing research indicate that the observed spatial variation in non-marital fertility can partly be related to the persistence of the past, as these patterns can be traced back over quite long time periods (e.g., Kok, 2009; Klüsener and Goldstein, 2014). In some countries the spatiotemporal pattern of the recent increases in non-marital fertility closely resembles the spatiotemporal pattern observed in the fertility decline during the demographic transition (see, e.g., Lesthaeghe and Neels, 2002, on Belgium and France). This suggests that some regional populations might be more receptive to new family formation trends than others, and that these differences could persist over time. My main aim in this article is to take a closer look at past path dependencies by providing a geographically detailed descriptive account of non-marital fertility levels and trends across Europe over the last 100 years. A secondary aim is to explore the question of what kind of regional variation in non-marital fertility might establish itself across Europe and within European countries once the current transition to higher non-marital fertility levels has come to an end. The focus of my analysis of the future of within-country variation will be on Denmark, the first European country to have completed an s-shaped transition from low to relatively high non-marital fertility levels, with the increase in the non-marital fertility ratio levelling off at around $50 \%$ in the late 1980 s. Thus, relative to countries which are still undergoing the transition, Denmark may be expected to have a rather mature spatial non-marital fertility pattern that is less affected by the spatially dependent so-

\footnotetext{
${ }^{1}$ The GIS-base maps used in this publication are partly based on the following source: ๑ EuroGeographics for the administrative boundaries.
} 
cial diffusion processes which are likely to occur during the transition. ${ }^{2}$ As a result, the analysis of the Danish case may be expected to provide insights into the kinds of spatial variation patterns which might emerge in other countries after they have completed the transition.

\section{Theoretical considerations}

The process that leads to a non-marital birth can be related to both individual-level attributes of the parents and contextual conditions, such as the socio-economic situation, policies and legislation of the country or region in which the birth takes place (Cutright, 1971; Lesthaeghe and Neels, 2002). Spatial variation in levels of non-marital fertility might therefore reflect spatial variation in the compositional characteristics of populations, as well as variation in contextual conditions. As my goal in this paper is to provide a general overview of spatiotemporal aspects of non-marital fertility trends across Europe over the last 100 years, the analysis that follows cannot address in detail the question of how the relative importance of each specific determinant has varied across space and time. Yet, when interpreting the findings it is important to be aware that a non-marital birth may reflect very different motivations and circumstances.

Particularly in a historical perspective, non-marital fertility has often been related to restrictions in the available options: for example, the mother may not have been in a stable relationship or the couple may have been denied the right to marry (see, e.g., Knodel, 1967; Kok, 2009). Today, having limited access to income might lead cohabiting couples to postpone marriage until they have established themselves in the labour market. Thus, non-marital fertility may increase sharply during periods of economic crisis (Abrahamson, 2000; Perelli-Harris and Gerber, 2011). In line with the assumption that non-marital fertility is associated with a pattern of disadvantage, many studies based on individual-level data-including some recent analyses - have shown a negative social status gradient in the likelihood of a non-marital birth (e.g., Perelli-Harris et al., 2012). The analysis of non-marital fertility is, however, complicated by the fact that, particularly as societies modernise, rising non-marital fertility may reflect not only limited options, but also the expansion of positive freedoms (Berlin, 1958). If, for example, women become more economically independent as a result of improved access to the labour market, they may also become less dependent on kin relations and the institution of marriage to secure their own livelihood and the livelihoods of their offspring (McLaughlin and Glendinning, 1994).

In terms of the potential historical path dependencies of countries and regions, there are different mechanisms through which social norms are transferred and upheld across space and time. Religious institutions, for example, tend to have rather time-invariant views on what

\footnotetext{
${ }^{2}$ See Hägerstrand (1965) and González-Bailón and Murphy (2013) for general considerations.
} 
constitutes proper family formation behaviour. All of the important religious institutions in Europe have, at least historically, taught that childbearing should occur within marriage. However, over the last centuries secularisation processes have limited the ability of many religious institutions to influence family formation behaviour. Thus, increasing non-marital fertility might reflect such secularisation processes through which the traditional norms supported by religious institutions lose relevance (Lesthaeghe, 2010). As spatial variation in secularisation processes exhibits in many regions of Europe path dependencies (Kaufmann et al., 2012; Klüsener and Goldstein, 2014), this might contribute to path dependencies in spatial variation of non-marital fertility pattern.

The institutional context might also contribute to path dependencies. Family law is one of the oldest areas of law, and regulations vary substantially across European countries (see PerelliHarris and Sánchez-Gassen, 2012). Most countries show substantial path dependencies in the development of their family legislation. This is also the case for general principles of the welfare state organisation, the foundations of which were first laid in many European countries in the late $19^{\text {th }}$ century. In the German-speaking countries, for example, welfare support has long been linked to the family via the married (male) breadwinner, as, based on subsidiarity considerations, the family was seen as the principal unit for dealing with issues related to bringing up children. Scandinavian countries, on the other hand, adopted very early individualistic support schemes and fostered in the same time female employment (see also Kolbe, 2002). These policies strengthened the economic position of women, and may have contributed to the fact that the Scandinavian countries have been forerunners in the recent increase of nonmarital fertility. In most European countries family legislation and welfare state institutions are organised at the national level. According to Watkins (1991) this has contributed to decrease regional differences in family formation pattern within countries in the $20^{\text {th }}$ century, an aspect for which she also provides empirical support. Regional convergence in demographic behaviour within nation states was, however, not only fostered by family policies and harmonisation of family legislation. Also the establishment of state-wide education systems that often privileged a common state language(s) and investments in national transport infrastructures contributed to a situation in which communication is more dense within countries than across country borders. This might also have an impact on the spread of new family formation pattern in space and time (Decroly and Grasland, 1993).

In terms of the transmission of family formation norms from the older to the younger generations, some spatial contexts might offer women and couples more freedoms than others to reject or ignore traditional social norms, including the norm that a woman should marry before having a child. In contexts with strong family ties (Reher, 1998) and inter- and intragenerational social control networks, such as the Mediterranean countries or rural areas, it might take longer for deviant family formation behaviours to spread as actors who consider such strategies might face or fear high losses of social capital (Bourdieu and Wacquant, 
1992). This could in turn have repercussions for the individuals' access to financial resources (employment opportunities, disinheritance, etc.). The situation might be different in spatial contexts in which these kinds of social control mechanisms are less prevalent (e.g., in anonymous cities or contexts with weak family ties).

In the scientific discussion, the concept of family systems is intended to capture this mix of macro-level and micro-level factors discussed above which might contribute to the persistence over time of the family formation practises of specific regions and countries (Kok, 2009). In this analysis, I will examine to what degree a persistence of the past is also visible in recent non-marital fertility developments, and whether the relevance of historic path dependencies varies across Europe.

\section{Data and methods}

\subsection{Data}

To investigate variation in non-marital fertility, I focus in this study on the non-marital fertility ratio, which is defined as the number of non-marital live births divided by the total number of live births. This measure is a rather crude indicator of non-marital fertility, as it does not allow me to control for age structure, migration background, educational attainment, or differences in the number of married and unmarried women between regions or in a region over time. The data also cannot be used to identify childbearing within cohabitation, or to investigate how this behaviour has become more prevalent in recent decades (see Perelli-Harris et al., 2012). Yet the big advantage of the non-marital fertility ratio is that it is available at a high degree of geographic detail for almost all European countries over long periods of time.

The data used for the analysis were collected by the statistical offices of the observed countries. For the period around 2007, the data were obtained directly from these primary sources, while the data for earlier periods were in part also derived from secondary resources (see section 6.2.1 in the references for details). The data for the period around 1910 were in part prepared by the collaborators of a project investigating the European infant mortality decline at high geographic detail (Klüsener et al., 2014), who kindly shared their data with me. The regional data for the developments since 1960 were mostly derived from a data collection compiled by the Atlas de la Population Européenne-project (Decroly and Vanlaer, 1991). These data were complemented with annual country data for the period 1960 to 2007, which were obtained from Eurostat, the Demographic Yearbook of the Council of Europe (2005), and Demoskop Weekly (2015).

As to the 1910 data it is important to note that the quality of population statistics varied substantially across Europe at that time (Edge, 1928; SGF, 1907). While countries in Northwestern Europe including Germany had already quite efficient registration systems in place, many 
countries in Eastern and Southern Europe had problems with the under-registration of vital events. This was particularly true for births in which the child died within the first days of life. As children born outside of marriage had often higher risks to die as infants, this might have affected the non-marital fertility ratio. Also within Northwestern Europe registration standards differed as some countries such as France, Belgium and Netherlands registered live births as stillbirths if they died before the registration of the births (Klüsener et al., 2014). As any attempts to correct for variation in registration standards would be based on bold assumptions, I decided to use the data without modifications assuming that in areas in which there was higher acceptance for a birth outside of marriage it was also more likely to be reported. Nevertheless, in interpreting the outcomes it is important to keep in mind that the analysis of regional path dependencies presented in this paper is looking at path dependencies in registered nonmarital fertility.

The demographic data were matched to GIS shapefiles which provide information on the administrative boundaries of the regions for which the demographic data were collected. These shapefiles were derived from the MPIDR Population History GIS Collection (MPIDR 2014ac), national historical GIS projects (see section 6.2.2 of the references for details), and the GADM database of Global Administrative Areas (2012).

\subsection{Generating estimates for a time-constant regional division of Europe}

One major challenge for research on historical regional path dependencies in Europe is the fact that there have been substantial changes in national borders and regional administrative boundaries over the last 100 years. This is particularly the case for Central and Eastern Europe. To facilitate the comparison over time, efforts have been made to derive estimates for a time-constant regional division of Europe. For the period 1960-2007, this study benefits from the fact that such a dataset has already been derived by Klüsener et al. (2013) for their paper on regional aspects of non-marital fertility trends since $1960 .^{3}$ This dataset covers most European countries using the current regional administrative division, while in some exceptional cases other divisions which existed at some point in time during the period 1960-2007 are used. $^{4}$ This dataset I complemented with data for the period 1910. In estimating non-marital fertility levels for the time-constant regions in 1910, a simple spatial interpolation method based on area weighting is used (Goodchild and Lam, 1980). ${ }^{5}$ The central assumption of this

\footnotetext{
${ }^{3}$ The shapefiles and the data have been downloaded from the following webpage: http://www.demogr.mpg.de/de/ausbildungkarriere/was_ist_demografie_1908/kinder_ja_ehe_nein_daten_3 $\underline{010 / \text { default.htm }}$

${ }^{4}$ At either the NUTS-2 or the NUTS-3 level, depending on which division is historically and/or politically more meaningful (see Klüsener et al., 2013, for details).

${ }^{5}$ Klüsener et al. (2013) used the same approach to derive their dataset for the period 1960-2007.
} 
method is that the marital and non-marital births are homogenously distributed across space, both within the so-called source regions for which data are available for a given year, as well as in the time-constant target regions for which estimates have to be produced. This sounds like a strong assumption, as it is not reasonable to expect that either the population or the births were homogenously distributed across a regional territory. However, it is important to point out that the bias produced by such an estimation is largely dependent on the geographical extent of the source in comparison to the target regions. The smaller the source and the larger the target regions, the smaller the bias which is introduced by this spatial interpolation technique. In this case, data on live births and non-marital live births were available for more than 5,000 source regions for the period 1910 in order to derive estimates for 604 target regions. Thus, the expected bias introduced by this approach is expected to be rather low. ${ }^{6}$ Estimates are derived by intersecting a GIS-polygon file with the boundaries of the source regions with a GIS-file of the target regions in order to obtain the smallest common polygons. The area information from these polygons allow me to generate the estimates for the target regions.

\subsection{Analytical Strategy}

The analysis is divided in three parts. The first introductory part (section 4.1) provides an overview on non-marital fertility trends in big European macro regions since 1960, followed by a geographically detailed account of present spatial variation in non-marital fertility across Europe. In the second part (section 4.2) I will explore to what degree historical regional path dependencies might be relevant for understanding present-day spatial variation across Europe. For this I asses how current spatial variation pattern correspond with pattern observed 100 years ago and at other points in time over the last 100 years. This is followed by the last part (section 4.3) in which I will discuss potential future pathways of spatial non-marital fertility variation across Europe.

Throughout the analysis, I make use of descriptive methods and cartographic representations. In the second part, correlations between regional non-marital fertility levels in the years 1910, 1960, 1975, 1990 and 2007 will be presented. For the years 1960-1990 this will only be possible for a reduced sample as I lack regional data for a number of Eastern European countries in this period. ${ }^{7}$ As most of the variables are positively skewed, Spearman's order rank correlation coefficient has been chosen to derive the correlations. If historical path dependencies play a role, it may be generally expected that a positive association would be found between the

\footnotetext{
${ }^{6}$ However, in the 1910 file the geographic detail varies to some degree across countries. Thus, the estimates are better for some parts of Europe than for others. I will come back to this issue in the presentation of the results.

${ }^{7}$ Details will be given when the results are presented.
} 
regional non-marital fertility levels in different years. This part of the investigation took inspiration from an analysis of path dependencies in non-marital fertility at the national level by Kok (2009). In his paper he used a sample that consisted predominantly of Western European countries to look at non-marital fertility levels in the period 1900 until 2000.

As the relevance of path dependencies is likely to vary spatially across Europe, I will derive in addition statistical associations for different subregions of Europe. This analysis will focus on contrasting variation in 1910 and 2007. In order to derive information on how the association between non-marital fertility levels in these two periods varies across Europe, I apply Geographically Weighted Regression techniques (GWR) (Fotheringham et al., 2003). The latter are in principle a series of local regressions which have their origins in moving-window regression methods. In this analysis, the dependent variable will be the non-marital fertility ratio in 2007, while the non-marital fertility ratio in 1910 will serve as the explanatory variable. The latter will be log-transformed to bring its distribution closer to a normal distribution.

For each region i in the sample, a local regression is carried out which includes values of the variables of interest for the region $i$ itself and for neighbouring regions $j$ situated in the adjacency of region i. ${ }^{8}$ This implies that for the derived European sample of time-constant regions in 1910 and 2007, a total of 604 local regressions will be calculated. In deciding which of the neighbouring regions to include in the local regressions, GWR offers the option of working with either fixed or adaptive bandwidths. In the case of the fixed bandwidth, the derived bandwidth is a fixed distance radius. All regions $\mathrm{j}$ whose geographical centroids are within the radius around the centroid of region i are included in the local regression for region $i$. In the case of the adaptive bandwidth, the derived bandwidth provides the number of nearest neighbours to be included in the regression (e.g., the 20 nearest neighbouring regions). For this analysis, I chose to use the adaptive bandwidth approach, as it would allow me to better account for the considerable variation in the sizes of the regions across the European sample. With a fixed bandwidth, the number of regions included in the local regression would have varied substantially between the densely populated areas in Central Europe and the sparsely populated parts in Northern or Eastern Europe where regions cover substantially bigger areas. In defining the number of neighbours to be included in each local regression it is in principle possible to work with an arbitrary adaptive bandwidth, which could be, for example, 20 or 25 nearest neighbours. Beyond that, GWR also allows for cross-validation or AIC-based procedures which derive an optimal bandwidth from the general properties of the model and the included variables. This optimal bandwidth constitutes a trade-off between the necessity to have enough observations in the local model to obtain statistically meaningful model outcomes, and the objective not to include too many distant observations in the local regression.

\footnotetext{
${ }^{8}$ The spatial distances between regions are derived by calculating the spherical distances between the regional geographical centroids.
} 
For this analysis I chose the cross-validation algorithm, as implemented in the $\mathrm{R}$ package GWmodel (Gollini et al., 2014).

In addition to using a bandwidth that defines which neighbours to include in the local regression, the GWR applies weights that give neighbouring regions $\mathrm{j}$ which are closer to the region $\mathrm{i}$ on which a specific local regression is centred more weight than more distant regions $\mathrm{j}$. This approach is in line with Tobler's first law of Geography; i.e., that "everything is related to everything else, but near things are more related than distant things” (Tobler, 1970). Different options for deriving these weights are available (see Gollini et al., 2014). This analysis follows a standard procedure of applying a Gaussian-shaped kernel centred on region i to derive the weights for the neighbouring regions $\mathrm{j}$. For the calculation of the GWR, the R package spgwr (Bivand et al., 2014) is used. Compared to the GWmodel package, this package offers some additional model diagnostics.

The GWR analysis allows to derive for each of the 604 regions the local r-squared of the local regression and the local beta estimates for the statistical association of the explanatory variable non-marital fertility in 1910 with the dependent variable non-marital fertility in 2007. These outcomes will be mapped to investigate how the statistical association between these two variables and the explanatory power of the local models vary across Europe. In interpreting the results, it is important to be aware that the outcomes of the local regressions are likely to be affected by spatial autocorrelation, which can cause substantial bias in the estimates derived from the regression models. This is particularly likely for those local regressions which include regions belonging to different countries. If, for example, a local regression is carried out in the border region between the Netherlands and Germany, it is likely that the assumption that all of the observations are independent from each other will be violated. Following the considerations by Watkins (1991) discussed above, Dutch regions tend to be more similar to each other in contrast to the German regions as they have been subject to a uniform set of national policies and regulations. This also contributed to create a rather clear cultural border line between the Netherlands and Germany which was not to that degree existing in earlier periods. It would be possible to account for this by adding country dummies to the GWR analysis. However, one problem with such an approach is that these country dummies might account for precisely the kind of variation I am interested in, as the differences between countries in 1910 in how childbearing outside of marriage was perceived might have an influence on non-marital fertility developments until today. A second problem is that, particularly in Eastern Europe, many regions belonged to one state in 1910 and a different state in 2007. Thus, I had to decide whether to use the country dummies of 1910 or 2007. A third problem is that adding country dummies to a GWR is likely to cause local collinearity problems which make the GWR outcomes unstable. After considering these challenges, I chose to use country dummies only for sensitivity analyses. 
In assessing what kind of bias spatial autocorrelation might introduce in the model estimates, it is helpful to evaluate whether this spatial autocorrelation stems rather from spatial dependence or rather from spatial heterogeneity (see Anselin, 2006). Spatial dependence refers to small-scale spatial dependence, which originates from unobserved social interaction between neighbouring regions. Spatial heterogeneity, on the other hand, refers to heterogeneity between bigger clusters of regions which is unlikely to be caused by direct unobserved social interaction processes between neighbouring regions. ${ }^{9}$ As discussed above in the example of the Dutch and German border regions, and following theoretical considerations by Watkins (1991), it may be assumed that most of the spatial autocorrelation derives from differences between nation-states in how non-marital childbearing is perceived and treated. Thus, I assume that the spatial autocorrelation stems rather from spatial heterogeneity between groups of regions that belong to the same country than from unobserved social interaction between neighbouring regions. This is also supported by outcomes of an analysis by Klüsener et al. (2013) which showed that most of the existing regional non-marital fertility variation is between-country variation, while there is rather little within-country variation. ${ }^{10}$ The advantage of spatial heterogeneity relative to spatial dependence is that the regressions remain unbiased in terms of the obtained beta estimates (Anselin, 2006). This is reassuring, as the main purpose of the GWR is to assess the magnitude and sign of the derived local beta estimates for the non-marital fertility levels in 1910. However, spatial heterogeneity can make the regression inefficient in terms of the estimated significance levels and r-squared values. In the case of politically induced spatial autocorrelation, the autocorrelation is most likely to be positive $^{11}$, which implies that regions with similar features are clustering in space. If positive spatial autocorrelation is present, the bias introduced in a linear regression is towards obtaining too high significance levels and inflated r-squared values (see Bivand et al., 2013). Thus, in interpreting the GWR outcomes in the results section it is important to be aware that high local r-squared values can be the result of a strong statistical association between the variables

\footnotetext{
${ }^{9}$ These two concepts are rather fluid and empirical studies based on spatial data are usually confronted by a mixture of these two effects. Thus, these considerations are focused on determining whether one of the two effects is likely to dominate over the other.

${ }^{10}$ The reader might see here a contradiction in my arguments as I stated above in the motivation of the Danish case that during the transition to higher non-marital fertility levels spatial diffusion pattern might occur. The latter are likely to exhibit a spatial dependence structure. I agree with this critique, but take at least to some degree assurance from the analysis outcomes by Klüsener et al. (2013) that these diffusion pattern within countries are not very dominant in contrast to the large variation which can be found between countries.

${ }^{11}$ The opposite to positive spatial autocorrelation is negative spatial autocorrelation. In the latter case regions with comparatively high values in the variable of interested are surrounded by neighbouring regions with comparatively low values. Negative spatial autocorrelation would have conservative effects on parameter estimates.
} 
of interest or an artefact of spatial autocorrelation, while low local r-squared values are indeed an indication of a low statistical association between the variables of interest.

\section{Spatial variation in non-marital fertility across Europe in historical perspective}

\subsection{Recent trends and present variation}

\subsubsection{Non-marital fertility trends in European macro regions since 1960}

In presenting the results, I will first discuss non-marital fertility trends for broad European macro regions over the last 50 years. This will allow me to describe regional variation in the timing and pace of the departure from the Golden Age of Marriage of the mid- $20^{\text {th }}$ century. The categorisation of European countries into macro regions was based on similarities in their welfare state systems (Esping-Andersen, 1990), and on other parallels in political developments over time. The macro region of Northern Europe represents the Nordic countries, which have extensive welfare state support systems (Esping-Andersen, 1990). The Western Europe region is comprised of countries which either have quite liberal welfare states (UK, Ireland, the Netherlands), or have long provided very high levels of child care support which might have positively affected the economic independence of women (France and Belgium). The third region of Central-Western Europe includes the German-speaking countries of Europe, which, apart from the former German Democratic Republic, have rather conservative welfare states (Esping-Andersen, 1990). These conservative welfare regimes are characterised by family support geared towards married couples and a temporal delay in the implementation of policies aimed at supporting the reconciliation of family and work. The Central-Eastern and Eastern Europe categories cover all of the former communist countries except for the German Democratic Republic. ${ }^{12}$ All of the former Soviet republics which are not currently part of the European Union ${ }^{13}$ have been assigned to the Eastern Europe category, while the other countries have been grouped in the Central-Eastern Europe category. The region of Southern Europe is comprised of countries whose populations exhibit strong family ties (Reher, 1998) and which, at least until recently, have been characterised by rather conservative welfare states (Esping-Andersen, 1990). In addition to data on the non-marital fertility trends for these six macro regions, also data for Europe as a whole have been derived. The resulting numbers are shown in Figure 1, in which the small map in the upper left corner indicates which European country has been linked to which macro region. ${ }^{14}$

\footnotetext{
${ }^{12}$ The latter has been included in the Central-Western Europe region as its territories became part of the Federal Republic of Germany in 1990.

${ }^{13}$ The numbers for Russia cover all of Russia, including the Asian part.

${ }^{14}$ See also annotations to Figure 1.
} 
Figure 1: Development of the non-marital fertility ratio in European macro regions

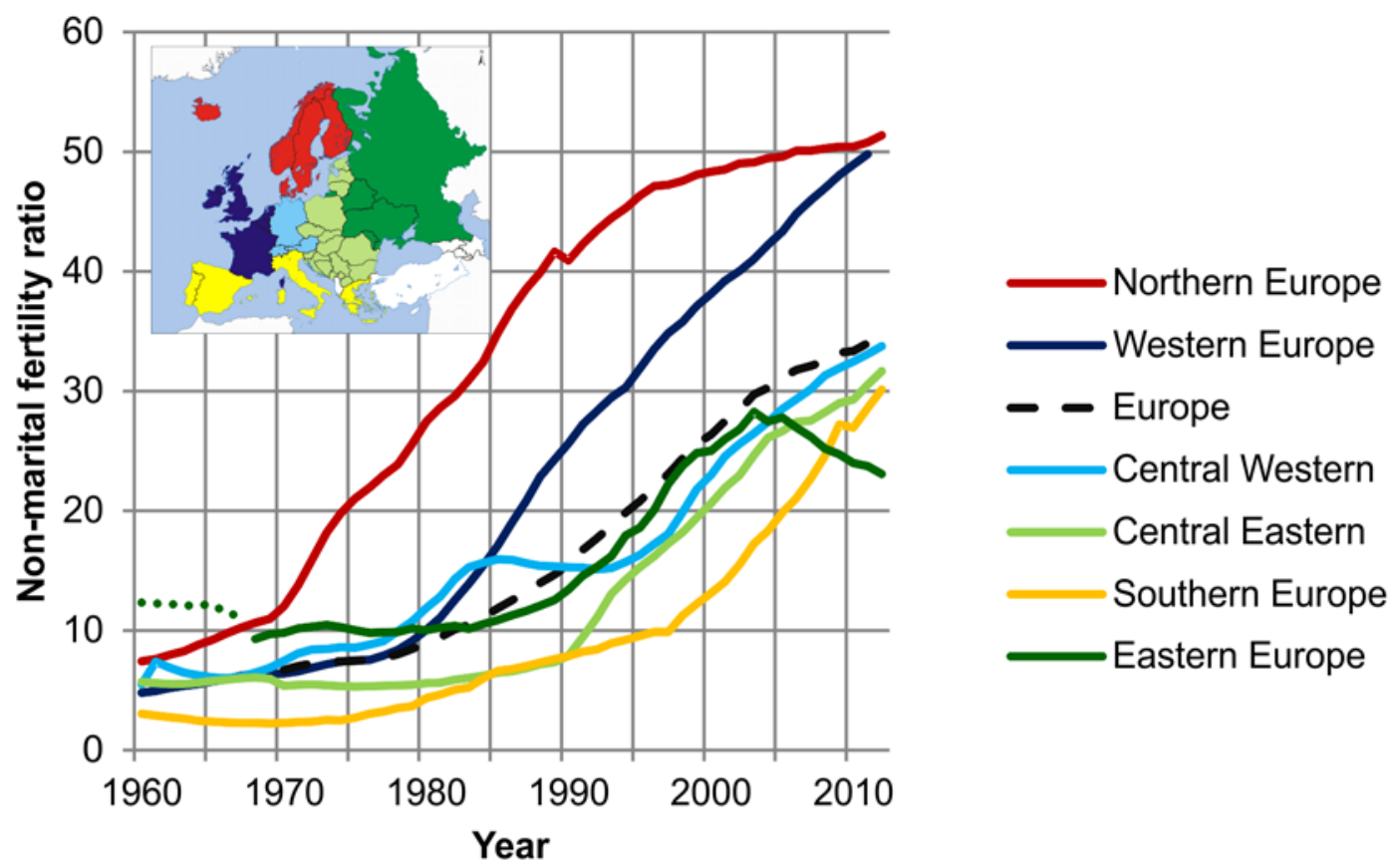

Note: Numbers for Eastern Europe exclude Ukraine until 1968 (dotted line) and Moldova until 1971.

Source: Statistical Offices; Eurostat; UN Statistical Yearbooks; Decroly and Vanlaer (1991); Council of Europe

The time series starts in the heyday of the Golden Age Marriage. Around 1960, all six macro regions but Eastern Europe had non-marital fertility ratios below 10\%. The first region to report dramatic increases was Northern Europe, where the transition started in the 1960s and gained additional momentum in the 1970s. By the late 1970s, the shares of births outside of marriage had also started to grow in Western and in Central-Western Europe. But unlike in Western Europe, the increase in Central-Western Europe was initially short-lived, and was mostly driven by developments in the German Democratic Republic and Austria. The areas of these two countries had also historically been hot spots of non-marital fertility (see below) which made their populations perhaps particularly susceptible to experience an early departure from the Golden Age of Marriage. After the GDR and Austria had introduced rather generous support schemes for single mothers ${ }^{15}$ in the 1970s, shares of non-marital births started to rise in these two countries. However, in the mid-1980s these support schemes were extended to married mothers (GDR) or restricted to non-married mothers without a partner (Austria).

\footnotetext{
${ }^{15}$ When I point in this paper to the temporal coincidence of legislative reforms and trend changes in nonmarital fertility in specific countries, this does not imply that the trend changes are caused by these legislative reforms. Causality can also exist in the opposite direction as shifts in family formation strategies can provide motivation for legislative reforms to adopt legislation to the newly emerging pattern of behaviour.
} 
After the implementation of these reforms the increase came in both countries at least temporarily to a halt (see also Kytir, 1992, and Klüsener and Goldstein, 2014). ${ }^{16}$

The decline in non-marital fertility in Central-Western Europe in the 1980s and the early 1990s was also related in part to compositional factors: i.e., East Germany, which had rather high shares of non-marital births, went from having fertility rates which were close to replacement level in the early 1980s, to having extremely low fertility rates in the 1990s (Goldstein and Kreyenfeld, 2011). As a result, Central-Western Europe went from being a forerunner in the transition to being a laggard. In the Central-Eastern and Eastern European regions, the average non-marital fertility levels changed very little between 1960 and the mid-1980s. Southern Europe had on average the lowest non-marital fertility rates of all of the macro regions in 1960, and these levels continued to decline until the 1970s. But in the 1970s, nonmarital fertility ratios started also to increase in Southern Europe, and have been rising ever since. However, the increases in the late 1970s and the 1980s were still quite small.

Thus, by the 1980s, the non-marital fertility levels of Northern and Western Europe were on a clear upward trajectory, while the levels of the other regions were lagging behind. The economic collapse of the Eastern Bloc in the late 1980s resulted in trend changes in these countries. During the crisis period that followed, non-marital fertility started to increase substantially in Central-Eastern and Eastern Europe. In Central-Western and Southern Europe, the trend towards higher non-marital fertility ratios also accelerated in the mid- to late-1990s. In some of these countries, such as in Germany, the acceleration of the trend occurred parallel to the enactment of legislative reforms which eliminated the legal discrimination of children born outside of marriage.

In the 2000s, the developments in Eastern Europe were probably the most remarkable of the trends which were unfolding across Europe. While all of the European macro regions had rapidly increasing non-marital fertility ratios in the late 1990s and early 2000s, Eastern Europe started to deviate from these general trends from around 2003 onwards. Since then, nonmarital fertility levels have been on a downward trajectory in this macro region. This trend is detectable in Russia, Belarus, and Moldova, while Ukraine has just experienced a levelling off of increases in non-marital fertility. The deviating trend in Eastern Europe might be linked to two factors. In terms of economic influences it has been argued that non-marital fertility increases in Eastern Europe in the 1990s were in part the result of the insecure economic conditions in these countries at that time (Perelli-Harris and Gerber, 2011). Thus, the economic stabilisation of the 2000s might have contributed to decrease non-marital fertility levels again.

\footnotetext{
${ }^{16}$ Interestingly, also in France the increase in non-marital fertility gained momentum in the 1970s just after a substantial support scheme for single mothers had been introduced (Knijn et al., 2007). However, in contrast to the GDR and Austrian government, the French government did not later on enact legislation that had the potential to limit the increases in non-marital fertility.
} 
But beyond that it also seems that Eastern Europe has entered a period in which traditional norms are regaining relevance. This is, e.g., supported by evidence for de-secularisation trends (see, e.g., Evans and Northmore-Ball, 2012, on Russia), and visible in the enactment of legislation that aims to limit non-traditional family formation behaviour (e.g., in Russia).

Northern Europe has registered lower increases in recent years, which might imply that the transition to higher non-marital ratios might be close to completion in this part of Europe. In the other four regions, non-marital ratios are continuing to rise. Thus, with the exception of Eastern Europe, a convergence of non-marital fertility levels can currently be observed across Europe.

In terms of potential path dependencies, it is again Eastern Europe which stands out. While this part of Europe had the highest non-marital fertility ratios in the 1960s, it had the lowest ratios in 2012. Another region which experienced substantial shifts in its relative position is Western Europe. While this macro region was in the second-last position in 1960, current trends suggest that it will soon overtake Northern Europe to become the macro region with the highest non-marital fertility ratios.

\subsubsection{A geographically detailed view of non-marital fertility variation across Europe in 2007}

In order to study present-day variation in non-marital fertility levels at high geographic detail, I compiled information on the non-marital fertility ratio for more than 2,300 European regions and localities for the period around 2007. The resulting map is displayed in Figure 2. In interpreting the map, it is important to note that the level of spatial detail varies across countries, as I tried to obtain for each country the information with the highest level of detail available. ${ }^{17}$

The map shown in Figure 2 also supports the view that the spatial variation in non-marital fertility levels across Europe is far from random. In Northern Europe, hot spots with very high levels include Iceland and large parts of Sweden and Norway. Within Central-Eastern Europe, Estonia is by far the country with the highest non-marital fertility levels. In Western Europe, France has the highest non-marital fertility levels, with relatively little internal variation across its subnational regions. Other hot spots include the territory of the former German Democratic Republic in eastern Germany, and an area encompassing the southern part of Austria and eastern Slovenia. In Southeastern Europe, Bulgaria has exceptionally high nonmarital fertility levels.

\footnotetext{
${ }^{17}$ As including the boundaries of the regions in this map would have substantially affected its readability, I decided to display in the map only the county boundaries, and to include a map with the regional boundaries in the appendix.
} 


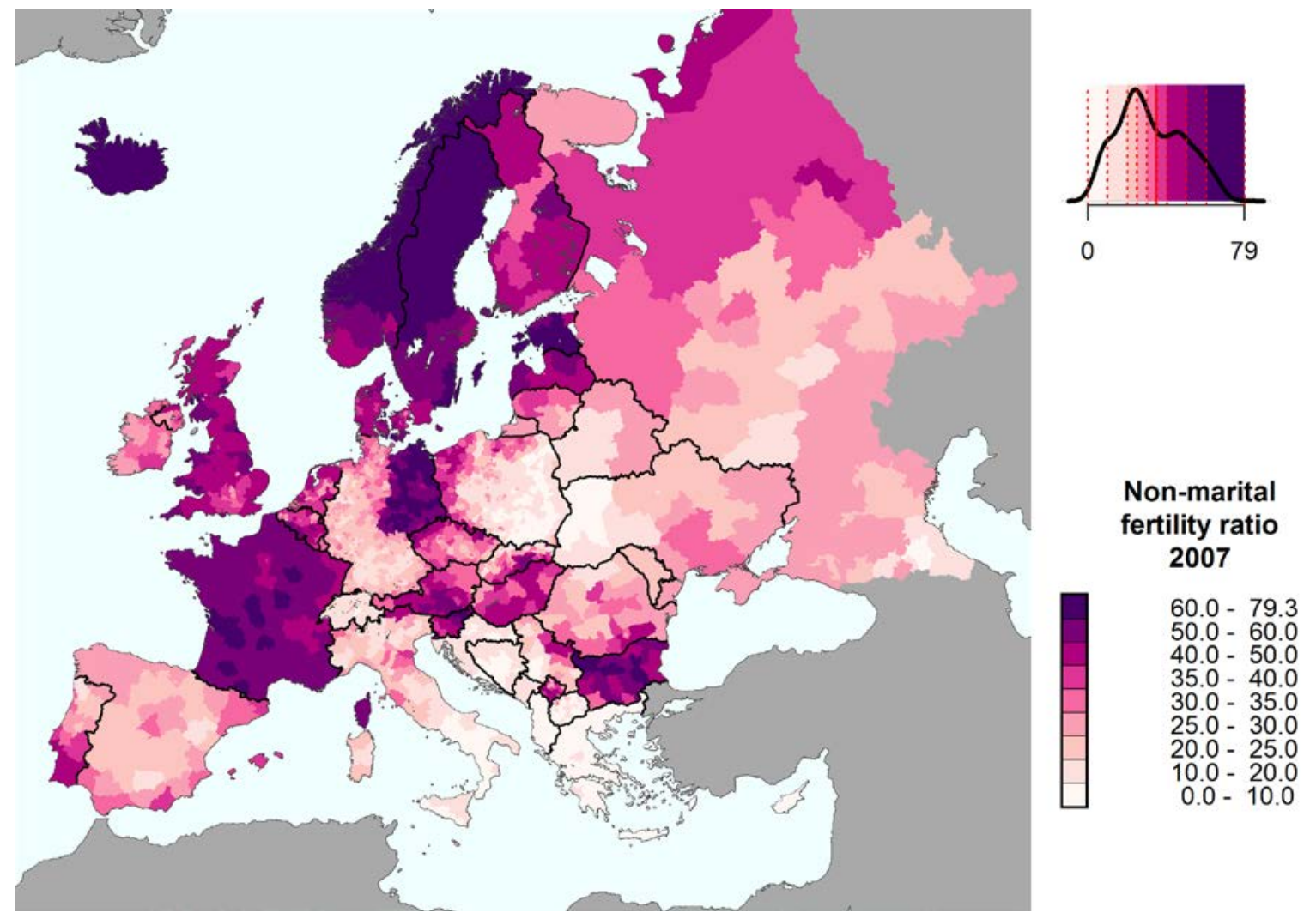

Note: The density curve in the upper right corner provides additional information to the legend given in the lower right corner by showing how the chosen colour categories relate to the distribution of the mapped variable.

Source: Statistical Offices; Eurostat, own calculations Base Map: MPIDR (2014a), partly based on EuroGeographics for the administrative boundaries; GADM (2012)

In many instances, patterns appear to be closely linked to national borders, even though the relevance of nation states for understanding non-marital fertility variation seems to have decreased in recent decades (Klüsener et al., 2013). There is, for example, a strong dividing line in non-marital fertility between France and Switzerland, despite the fact that the populations east and west of the border speak the same language. Existing research suggests that the nonmarital fertility divide along this border is largely a result of differences in family policies and family legislation between France and Switzerland (Perelli-Harris and Sánchez Gassen, 2012; Le Goff and Ryser, 2010).

A number of countries exhibit a significant degree of internal regional variation in non-marital fertility levels. These have in part historical origins far back in time. In Germany, for example, Klüsener and Goldstein (2014) showed that differences in non-marital fertility levels between the eastern and western parts of Germany can be traced back to the $18^{\text {th }}$ century. Poland is also an interesting case, as large parts of the areas which belonged to Germany until World War II, and were resettled after the war, have today much higher non-marital fertility levels than the other parts of Poland (see also Brzozowska, 2011). In Slovakia, there are stark differences between the northern and southern parts of the country, even though the north-south extension of this country is quite small: along Slovakia's border with Poland, the levels of 
non-marital fertility are, at $7 \%$ to $20 \%$, rather low; whereas in the southern part of Slovakia, the non-marital fertility ratios are, at $35 \%$ to $55 \%$, quite high. Another country with clear regional differences is Serbia: in that country, non-marital fertility levels are lowest in the mountain areas of the western Balkans along the border with Bosnia-Herzegovina and Montenegro, while they are highest in the Danube region along the borders with Romania and Bulgaria (Stanković and Penev, 2012). In Kosovo, the area populated by the Serbian minority stands out from the rest of the territory. However, the rather high levels reported in the Muslim-dominated rest of Kosovo are rather an artefact, as the statistical office of Kosovo treats births in common-law marriages as non-marital (see Klüsener et al., 2013, for details). If only births for which the father could not be determined were treated as non-marital, the nonmarital fertility ratio in Kosovo would be as low as it is in neighbouring Albania. Minority regions also stand out in other countries. In Italy, for example, South Tyrol exhibits levels that are very similar to those observed in neighbouring Austrian Tyrol.

There are also a number of clusters with similar non-marital fertility levels that extend across country borders. For example, there is an area with rather low non-marital fertility levels which stretches across the southeastern part of Poland and the western part of Belarus and Ukraine. This area of rather low levels roughly corresponds to the state boundaries of interwar Poland. Historical boundaries seem also to show up in other cases. In Italy, the areas with rather low levels of non-marital fertility are concentrated within the boundaries of the former Kingdom of Naples. These findings lend support to the argument that it is potentially a fruitful exercise to investigate to what degree current patterns might be linked to the historic path dependencies of specific European regions.

\subsection{Persistence of the past?}

In order to look into the potential longue dureé of regional pattern, I compare the spatial variation in 2007 with the patterns which existed around 1910. These historic patterns are displayed for more than 5,000 historical regions and localities in Figure 3. The spatial patterns in 1910 were also far from random. However, in virtually all of Europe, the non-marital fertility ratios were much lower in 1910 than in 2007. In line with the theoretical considerations of Watkins (1991), the political boundaries in the 1910 map are much less meaningful than those of the 2007 map for understanding the spatial patterns, as in the early $20^{\text {th }}$ century nation states were only starting to play an important role in shaping the demographic map of Europe.

In many cases, a specific pattern is not aligned with the boundaries of empires or nation states. This is, for example, the case for an area with rather low non-marital fertility levels which covered the Netherlands, the adjacent territories in western Germany, and, to some degree, Belgium. Similarly, there was a hot spot of non-marital fertility in Central Europe which covered southern Bavaria and the neighbouring territories of today's Austria. In these 
two territories high non-marital fertility was linked to inheritance practices and accompanying legislation (Shorter, 1978; Khera, 1981). While Austria also constitutes a non-marital fertility hot spot today, Bavaria has "converged" towards the levels reported in other parts of western Germany (see Figure 2). It is likely that this convergence trend was fostered by discontinuities in Bavarian civil legislation due to the introduction of a unified civil code in Germany in 1900. While Bavarian civil legislation had given children born outside marriage quite substantial rights, the German civil code explicitly stated that a child born outside marriage and his father are not related (see also Klüsener and Goldstein 2014).

\section{Figure 3: Non-marital fertility ratio 1910}

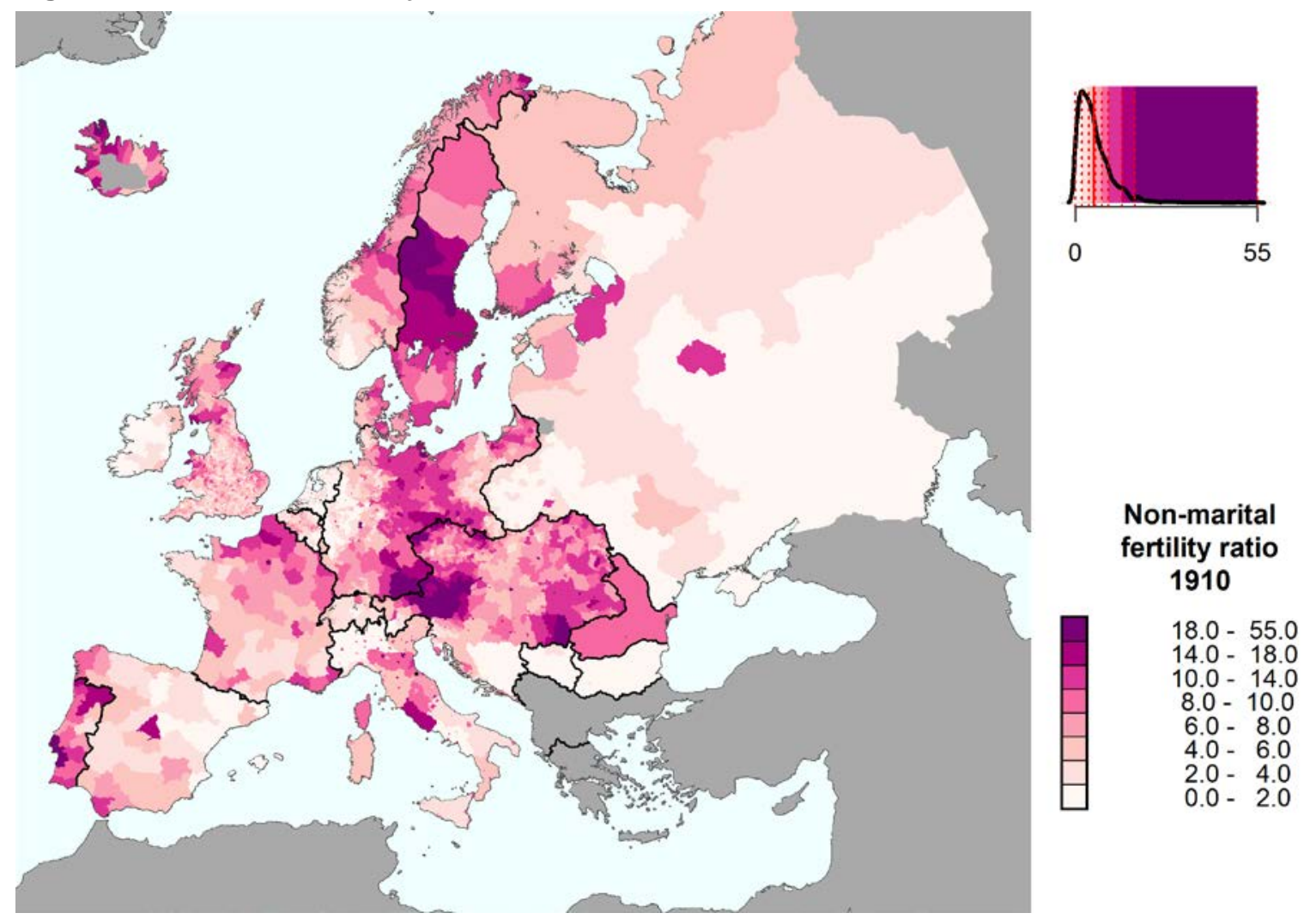

The density curve in the upper right corner provides additional information to the legend given in the lower right corner by showing how the chosen colour categories relate to the distribution of the mapped variable.

Source: Statistical Offices; Ekamper and van Poppel (2008); Devos (2014); Klüsener et al. (2014) Base Map: MPIDR (2014a-c), partly based on EuroGeographics for the administrative boundaries; National Historical GIS projects (see also section 6.2.2 of references for details)

In the map of 1910, capital areas or big cities tend to stand out as singular non-marital fertility hot spots within a country. This was, e.g., the case for Madrid in Spain, St. Petersburg and Moscow in Russia, and Rome in Italy. It seems that particularly in conservative countries such as those mentioned above, non-marital fertility was largely restricted to the relatively anonymous large urban centres. Today, on the other hand, big metropolitan areas often have lower non-marital fertility levels than their surrounding areas; an issue which I will discuss in more detail below, as I look at future pathways. 
I will now turn to the comparison of levels of non-marital fertility levels for the 604 timeconstant regions for which values and estimates of non-marital fertility levels are available for 1910 and 2007. For a reduced sample of 482 regions which excludes a number of Eastern European countries $^{18}$, estimates for the years 1960, 1975, and 1990 are also available. Table 1 displays correlations for the regional non-marital fertility ratio in 1910 and 2007 for the full sample; and for the reduced sample correlations between 1910 and 1960, 1975, 1990, and 2007, respectively. The table shown here was constructed in a manner similar to that of a table presented by Kok (2009), in which he displayed the outcomes of a correlation analysis of non-marital births in 15 (mostly Western) European countries in 1870, 1900, 1930, 1960, and 2000. Kok used as well Spearman's order rank correlation coefficient. Although the correlations presented here cover a much larger part of Europe at a higher level of detail than those of Kok (2009), the obtained coefficients and trend patterns display many similarities. All of the correlation coefficients in Table 1 are in the expected positive direction. However, the correlation between 1910 and 2007 is rather low, with the obtained correlation coefficients being 0.29 for the full sample and 0.30 for the reduced sample.

Table 1: Rank order correlation (Spearman's rho) of regional non-marital fertility ratio (NMFR) in 1910, 1960, 1975, 1990, and 2007

\begin{tabular}{|c|c|c|c|c|c|}
\hline & NMFR 1960 & NMFR 1975 & NMFR 1990 & NMFR 2007 & NMFR 2007 \\
\hline & $N=482$ & $N=482$ & $N=482$ & $N=482$ & $N=604$ \\
\hline NMFR 1910 & 0.59 & 0.51 & 0.43 & 0.30 & 0.29 \\
\hline NMFR 1960 & - & 0.80 & 0.53 & 0.40 & - \\
\hline NMFR 1975 & - & - & 0.83 & 0.69 & - \\
\hline NMFR 1990 & - & - & - & 0.89 & - \\
\hline
\end{tabular}

Note: The reduced sample excludes Belarus, Romania, Russia, and Ukraine; for which no regionally detailed data are available for the years 1960, 1975, and 1990. Both the full and the reduced sample exclude an area in Southeastern Europe which is today covered by the countries Albania, Greece, Kosovo, the former Yugoslavian republic of Macedonia, Montenegro, and Turkey; as no data on the non-marital fertility ratios in this area are available for 1910 (see also Figure 4). For the same reason also some regions in the east and southeast of European Russia had to be excluded from the full sample. All of the European micro states-such as Andorra, Monaco, Liechtenstein and San Marino-are also excluded.

Source: Statistical Offices; Eurostat; UN Statistical Yearbooks; Decroly and Vanlaer (1991); Council of Europe (2005); Ekamper and van Poppel (2008); Devos (2014); Klüsener et al. (2014), own calculations

The comparison of correlations which were obtained between the regional non-marital levels in 1910 and the years 1960, 1975, 1990, and 2007 for the reduced sample show that the correlation with the 1910 values decreased over time. Similar trends of declining correlations are observable for the correlation of the regional levels in 1960 and 1975 on the one hand, and the levels in later periods on the other. These trends, which are also visible in the numbers pre-

\footnotetext{
${ }^{18}$ See annotations to Table 1 below for details.
} 
sented by Kok (2009), suggest that there are regional path dependencies, but that they are fading over time. ${ }^{19}$

As the correlations for Europe as a whole might hide regional variation in the association between non-marital levels in 1910 and 2007, I now turn to the outcomes of the Geographically Weighted Regression analysis (GWR). These results will allow me to study potential historical path dependencies at a high level of geographic detail. The input data and some main outcomes of the GWR analysis are displayed in Figure 4. Figure 4a shows the dependent variable, the non-marital fertility ratio in 2007, and Figure 4b the log-transformed values of the non-marital fertility ratio in 1910; this will be the only independent variable in the local regressions. Unlike the maps in Figures 2 and 3, these maps display the non-marital fertility ratio for the 604 time-constant regions. This way of presentation lacks spatial detail, but might facilitate the comparison of the regional levels in 1910 and 2007. Both maps are based on a standard deviation categorisation centred on the mean. Values above the mean are in green tones, while those below the mean are in brown tones.

The outcomes of the GWR analysis presented in Figures 4c and 4d provide the expected positive beta coefficient for most of the local regressions: i.e., that the levels in 1910 are positively associated with the levels in 2007. However, there are two areas which represent notable exceptions. One of these areas is situated in Southeastern Europe. There, Bulgaria has shifted from having extremely low to extremely high non-marital fertility levels, while the regions that today make up Romania had comparatively high levels in the past and quite low levels today. ${ }^{20}$ For this negative association, rather high local r-squared levels are also obtained. This is likely influenced by bias due to spatial autocorrelation, as the variation in this area is structured to a considerable degree by the Bulgarian-Romanian border. The second area for which negative coefficients were obtained is England and Wales. But in this area, the local r-

\footnotetext{
${ }^{19}$ A deviation from the outcomes presented by Kok (2009) is that all of the obtained correlation coefficients are significant, whereas Kok did not obtain significant results for correlations between the nonmarital fertility variation in 2000 and the variation in earlier periods. However, this difference might be related to the bigger sample size used in this analysis, as the correlation coefficients Kok obtained for 2000 and 1900 (0.44), and 1960, respectively (0.32), are close those presented in Table 1 for 2007 and 1910, and 1960, respectively. Another reason why the analysis based on the regional data returns a higher significance level is that spatial autocorrelation might inflate the returned significance level due to a violation of the assumption that all of the introduced regional values are completely independent of each other (see discussion in section 3.3).

${ }^{20}$ The estimation of non-marital fertility levels in 1910 for the time-constant regions in those areas that already belonged to Romania in 1910 was limited by the fact that the available data for the source regions only allowed to distinguish between Bucharest and the rest of the country. Thus, the rather homogenous 1910-estimates in Southern and Eastern Romania are an artefact of this limitation. However, as the discontinuity in the trend pattern is rather driven by the developments in Bulgaria, this should not affect the general outcomes of the GWR for this Southeastern European area.
} 
squared values are rather low. When I did consistency checks with country dummies, the coefficient for non-marital fertility in 1910 remained positive in almost all of Europe. However, in addition to the above-mentioned two areas with negative coefficients another area with negative coefficients shows up when country dummies are introduced. This area comprises Southwestern France and Northeastern Spain (Catalonia), which had both in an intra-country comparison rather low non-marital fertility levels in 1910, while they display comparatively high levels in 2007.

Figure 4: Geographically Weighted Regression: Non-marital fertility ratio in 1910 vs. in 2010

a) Non-marital fertility ratio 2007

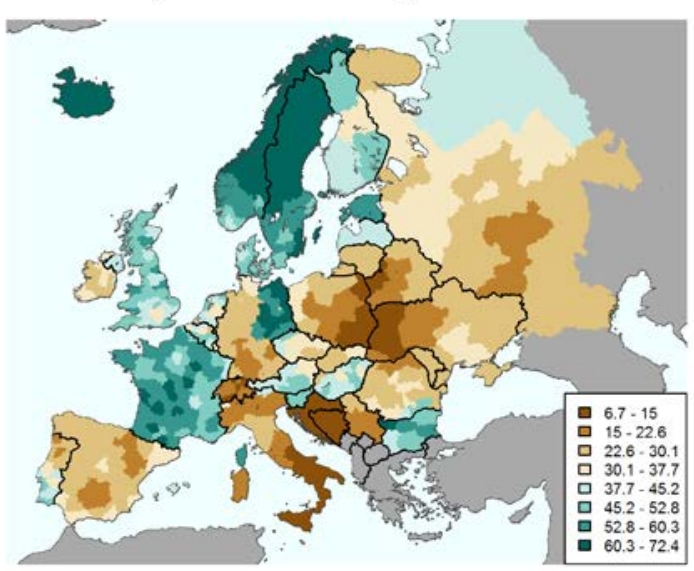

c) Beta coefficient Non-marital fertility ratio $1910(\mathrm{log})$

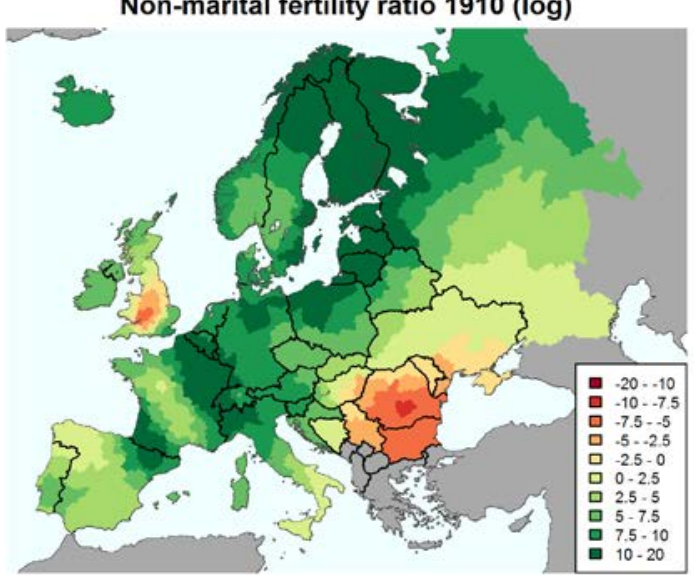

b) Non-marital fertility ratio 1910 (log)

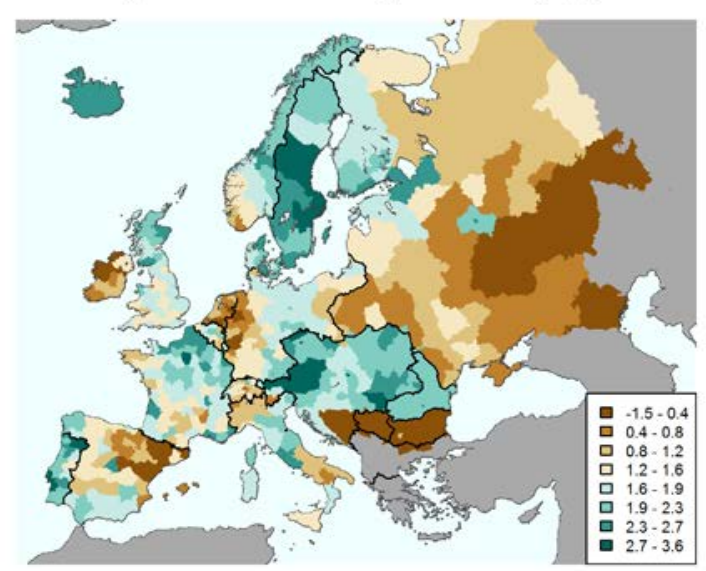

d) Local $\mathbf{r}^{2}$

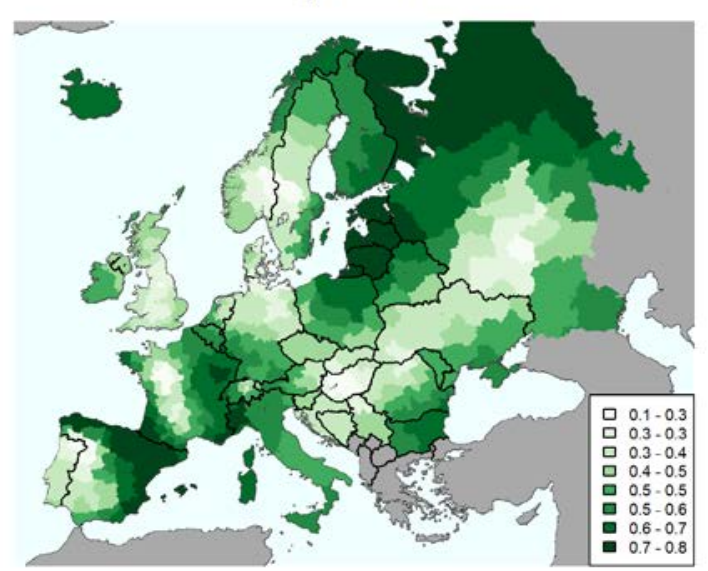

Source: Statistical Offices; Eurostat; UN Statistical Yearbooks; Decroly and Vanlaer (1991); Council of Europe (2005); Ekamper and van Poppel (2008); Devos (2014); Klüsener et al. (2014), own calculations Base Map: MPIDR (2014a-c), partly based on EuroGeographics for the administrative boundaries; National Historical GIS projects (see also section 6.2.2 of references for details)

In terms of potential explanations for the peculiar trends in Bulgaria, the existing literature highlights that the country has a long tradition of legislators aiming to actively influence family formation pattern in the Bulgarian society. This tradition started after Bulgaria's independence in the late $19^{\text {th }}$ century, when civil legislators did not proceed to develop civil legislation 
based on existing customs. Instead, for various reasons, they directly transferred legal norms from western civil legislation (see Todorova, 2000, for details). Also during the communist period civil legislation interfered quite strongly with existing practises. For example, in an attempt to preserve traditional family formation behaviour, non-married persons were forced to pay a bachelor tax which provided a strong financial incentive to marry (see also Brunnbauer and Taylor, 2004). These policies might have contributed to decouple the marriage decision from social norms and link it rather to economic considerations. ${ }^{21}$ This might have contributed to the particularly strong increases in non-marital fertility in Bulgaria in the unstable economic situation of the 1990s and 2000s when the bachelor tax was no longer in place.

The areas where the GWR returned relatively high positive beta coefficients include the regions around the Baltic Sea. In this area, the territories which were predominantly settled by Catholic populations (Poles and Lithuanians) had the lowest levels of non-marital fertility in both 1910 and 2007, while Sweden had the highest levels in both years. Very high beta coefficients were also obtained for the border region between France and Spain, and for the border region between France and its eastern neighbours of Germany, Switzerland, and Italy. These national borders correspond to strong dividing lines in non-marital fertility levels today, and exhibited already level differences in 1910, though to a much lesser extent. The outcomes for these two border zones are very similar to the results of an analysis by Bocquet-Appel and Jakobi (1996, p. 121), in which they used a wombling approach to identify zones which constituted at least temporary barriers to the spatial diffusion of the fertility decline as part of the demographic transition. The fact that these boundaries also show up in this analysis underlines their importance as demarcations between distinct zones which differ in terms of family formation behaviour and transitions to new patterns.

\subsection{Potential future pathways}

\subsubsection{Future patterns of between-country variation}

The discussion of future pathways is divided into two parts: potential variation across countries, and potential variation within countries. Existing research suggests that between-country variation of childbearing in cohabitation across Europe is linked to secularisation processes as well as to the economic autonomy of women (Lappegård et al., 2014). Patterns of disadvantage, on the other hand, seem to be more relevant for understanding variation between individuals and across sub-national regions (Lappegård et al., 2014). Projections by Kaufmann et al. (2012) indicate that the secularisation process has levelled off in countries with

\footnotetext{
${ }^{21}$ Salles (2006) argues in a similar vein as with regard to the German Democratic Republic.
} 
Protestant traditions, which were forerunners in this process ${ }^{22}$, while it is still on-going in countries with a Catholic tradition. Thus, Europe is currently witnessing a convergence in the secularisation levels of countries with Protestant and Catholic traditions, which might in turn contribute to a convergence in levels of non-marital fertility. However, as mentioned above, the situation is different in a number of Orthodox countries, particularly in Eastern Europe, which have rather seen a rise in religiosity since these countries broke with their secular Communist past (see, e.g., Evans and Northmore-Ball, 2012, on Russia). If this tendency towards increasing religiosity prevails in Eastern Europe, it might be expected that the already visible trend of a divergence of non-marital fertility levels between Eastern Europe and the rest of Europe might also continue in the future.

The economic autonomy of women is heavily influenced by welfare state institutions (McLaughlin and Glendinning, 1994). As there is currently a harmonisation of policy norms at the supranational level-through, for example, the European Court of Human Rights (Goldhaber, 2007) and the European Union-it appears likely that the relevance of betweencountry differences will continue to decline in the coming decades. Some indications that this is already occurring have been provided by Klüsener et al. (2013), who showed that, while the between-nation dimension of variation is still very dominant, its importance has been declining relative to that of the regional dimension between 1990 and 2007. Findings by Lappegård et al. (2014) have suggested that the association between the economic autonomy of women and high levels of non-marital fertility have been shaped by differences between Eastern and Western Europe, as support for female economic independence seems to be much lower east of the Hajnal line (Hajnal, 1965) than it is in Western Europe. Convergence in the levels of women's economic independence in the European Union member states may be expected to occur in the coming decades, which could in turn contribute to convergence in non-marital fertility levels. However, the non-EU part of Eastern Europe might again constitute an exception to these trends. Eastern European countries are less influenced by European institutions in the development of their welfare state and family legislation, although there might be to some extent effects via their membership in the Council of Europe. In general, it appears that the non-EU part of Eastern Europe is the area of the continent which is least likely to follow the trend towards convergence in family legislation and welfare state development. Thus, current indications that Eastern Europe has departed from the general transition towards high non-marital fertility ratios are, perhaps, not so surprising. Also European countries with a Muslim tradition show so far no evidence for strong increases in non-marital fertility. The only exception is the Kosovo, where the increase is, however, rather a statistical artefact. Thus, non-EU countries with an Orthodox or Muslim tradition seem to have the highest likelihood to return to or remain at rather low non-marital fertility levels.

\footnotetext{
${ }^{22}$ To this group of forerunners belonged also France, which was predominantly Catholic, but experienced early secularisation trends as a result of the French Revolution (Lesthaeghe and Neels, 2002).
} 


\subsubsection{Future patterns of within-country variation}

As I noted in the introduction, the exploration of potential future within-country variation patterns will focus on Denmark, which was the first European country to complete the transition from having rather low to having high levels of non-marital fertility. Figure 5 presents for the 99 Danish municipalities the non-marital fertility ratio which was derived based on the birth counts for the period 2007-2010. Interestingly, the highest non-marital fertility ratios were registered in the most central and the most marginal areas of Denmark. The first group of areas with high non-marital fertility consists of the municipalities in the centre of the metropolitan area of Copenhagen, while the second group is made up of the small Danish islands and the northern part of Jutland, which constitutes the continental part of Denmark. In both clusters of municipalities, more than $50 \%$ of all births were to non-married mothers. Meanwhile, the lowest levels of non-marital fertility were reported in the outer core and suburban belt of the Copenhagen metropolitan area.

Figure 5: Non-marital fertility ratio in Danish municipalities (2007-2010)

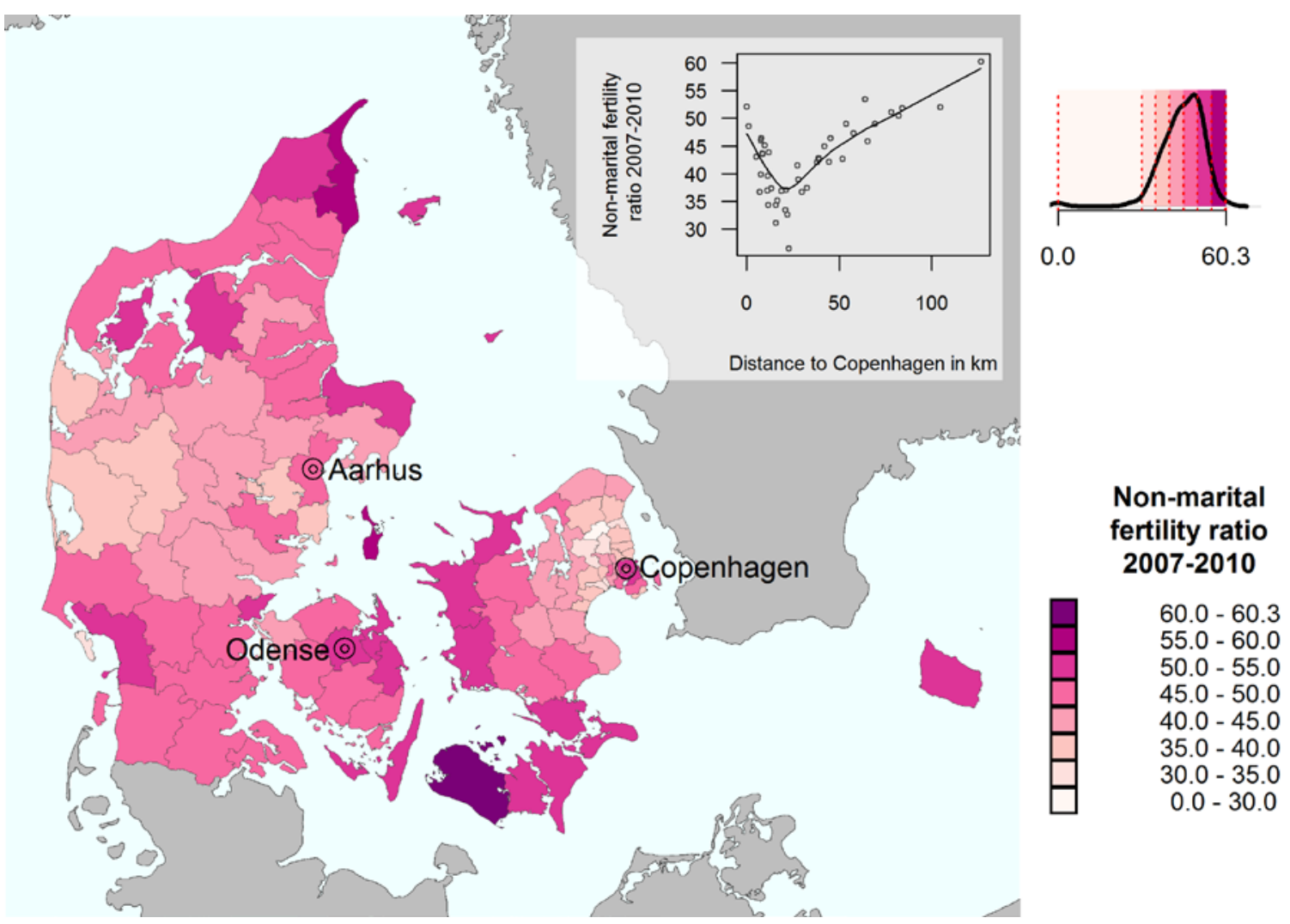

Note: The scatter plot displays the non-marital fertility ratio of regions within a distance of $120 \mathrm{~km}$ around the city of Copenhagen by distance to the geographical centre of the city of Copenhagen. The fitted line is a polynomial regression line obtained with a locally weighted polynomial regression (LOWESS) (Cleveland, 1979); the density curve in the upper right corner provides additional information to the legend given in the lower right corner by showing how the chosen colour categories relate to the distribution of the mapped variable.

Source: Statistics Denmark, own calculations Base Map: Dansk Center for Byhistorie (2010); MPIDR (2014a), partly based on EuroGeographics for the administrative boundaries 
For the island of Zealand, on which Copenhagen is located, and the smaller islands to the south of Zealand, the non-marital fertility patterns are reminiscent of those of classical spatial distribution models, such as the land use models suggested by Thünen (1826) or the city models by Burgess (1925): i.e., the non-marital fertility levels seem to vary systematically with the distance to the centre of the Copenhagen metropolitan area. To show this more clearly, a scatter plot has been added to the upper right corner of Figure 5, which displays the non-marital fertility ratios for areas within a distance of $120 \mathrm{~km}$ around Copenhagen by the distance to the centre of the city of Copenhagen. This plot benefits from the fact that Copenhagen metropolitan area is made up of several independent municipalities. Through these observations, a polynomial regression line was fitted using the LOWESS-smoother (Cleveland, 1979). This line exhibits a steep negative gradient from the rather high non-marital fertility levels in and around the city of Copenhagen, to the substantially lower levels in the outer core and suburban belt of the metropolitan area. However, starting at a distance of around $20 \mathrm{~km}$ from the city centre of Copenhagen, the levels are again increasing. At around $60 \mathrm{~km}$ from centre, levels similar to those in the city of Copenhagen are reached. Around the second biggest Danish city, Aarhus, municipalities in the suburban belt around the city again tend to have lower levels of non-marital fertility than the city of Aarhus itself or the more peripheral areas. In assessing whether this pattern is specific to Denmark, a challenge I faced is that most of the other countries have not completed the transition to high non-marital birth levels, or that there is a lack of the kind of fine-gridded data needed to distinguish between the inner and outer cores of large cities, and their suburban belts. However, it is possible to observe that in, for example, the United Kingdom and France, the metropolitan areas of London and Paris are among the regions with the lowest non-marital fertility ratio in an intra-country comparison (see Figure 4). At least for Paris and its surrounding regions, the pattern was the exact opposite in 1910.

The low non-marital fertility levels in the outer cores of the city centres of metropolitan areas and their suburban belts are probably to some degree the result of selective migration processes. Research has shown that metropolitan areas attract people with high levels of educational attainment (Buch et al., 2014), who often have a lower propensity to have a child outside of marriage (Perelli-Harris et al., 2010). The outer core of the city centre is also frequently an inmigration destination for foreigners. Members of these groups tend to have a lower tendency to give birth to a child outside of marriage (see, e.g., Klüsener and Goldstein, 2014, for Germany). This is not only linked to the fact, that migrants in Europe are frequently from regions of origin in which more conservative social norms regarding family formation behaviour are prevalent, but also because family reunion migration is facilitated by some European countries if a couple is married (for an overview, see Wray et al., 2014). Moreover, the social values of individuals might affect their migration decisions. For individuals who care about the traditional family formation norms which were most prominent during the Golden Age of Marriage in the 1950s and 1960s, suburbia with its access to well-paid jobs in the city and 
comparatively low housing prices might provide the ideal spatial context for living in accordance with these family ideals (see also Kulu, 2013). Meanwhile, people who favour alternative, non-traditional lifestyles, including childbearing outside marriage, might prefer to live in the city centre.

\section{Conclusion}

In this article, I explored the continuities and discontinuities in spatial variation in non-marital fertility across Europe over the last 100 years. Non-marital fertility has increased substantially since the temporal minimum in the Golden Age of Marriage in the 1950s and 1960s. The comparison of the spatial variation patterns in 1910 and 2007 suggests that path dependencies are relevant for understanding today's spatial variation in non-marital fertility levels. However, these path dependencies vary spatially and seem to be fading over time, as almost all of the European regions are now registering a transition to substantially higher non-marital fertility levels. But in Southeastern Europe, the analysis identified a region in which the current spatial variation patterns deviate strongly from the historic patterns. This deviation is related to developments in Bulgaria, which has gone from having very low levels of non-marital fertility to having comparatively high levels; a transition which seems to be related to sharp disruptions in family legislation and policies (see Todorova, 2000).

In terms of the future pathways of between-country variation, both the theoretical considerations and the observed trends suggest that most European countries will converge at rather high levels of non-marital fertility. The European integration process may be expected to contribute to this convergence, as it tends to promote the harmonisation of family legislation and the elimination of any remaining legal discrimination of children born outside of marriage. However, the non-EU part of Eastern Europe might constitute an outlier in this convergence trend, as it is currently the only European region which has declining non-marital fertility ratios. This development reflects a reactionary trend in non-EU former Soviet Union countries, in which religiosity has been rising and in which many people appear to be rejecting a wide range of family formation behaviours which are not in line with traditional norms. Another group of potential outliers might be countries of Europe with a Muslim tradition, where nonmarital fertility levels have remained so far very low-with the exception of the statistical artefact in Kosovo, which was discussed above. Thus, a dichotomy in non-marital fertility levels might emerge between the non-EU countries with Orthodox Christian or Muslim traditions, and the rest of Europe. However, it is also likely that different levels will continue to exist between EU countries even after they have completed the transition. For example, in Denmark the process levelled off some decades ago at a non-marital fertility ratio of $50 \%$, while in France the transition is not yet complete, but is currently at a level of 56\%. Within countries, it seems that in the future the outer city centre cores and the suburban belts of big 
metropolitan areas could become the last strongholds of marital fertility. This is to some degree a break with the past as big cities and their surrounding areas were in the early $20^{\text {th }}$ century rather hot spots of non-marital fertility.

\section{References}

\subsection{Literature}

Abrahamson, M. (2000). Case studies of surges in nonmarital births. Marriage \& Family Review, 30(1-2), 127-151.

Anselin, L. (2006). Spatial analysis with Geoda: 4: Spatial regression. Groningen: Spatial Economic Groningen. http://www.regroningen.nl/summerschool/ppt/4_spareg.pdf

Berlin, I. (1958). Four essays on liberty. Oxford: Oxford University Press.

Bivand, R. S., Pebesma, E., \& Gómez-Rubio, V. (2013). Applied spatial data analysis with R. $\left(2^{\text {nd }}\right.$ edition). New York. Springer Science \& Business Media.

Bivand, R., Yu, D., Nakaya, T., \& Garcia-Lopez, M.-A. (2014). 'spgwr': R package version 0.6-26. http://cran.r-project.org/web/packages/spgwr/index.html

Bocquet-Appel, J.-P., \& Jakobi, L. (1996). Barriers to the spatial diffusion for the demographic transition in western Europe. In J.-P. Bocquet-Appel, D. Courgeau, \& D. Pumain (Eds.), Spatial analysis of biodemographic data (pp. 117-129). Montrouge: John Libbey Eurotext.

Bourdieu, P., \& Wacquant, L. J. (1992). An invitation to reflexive sociology. Chicago: University of Chicago Press.

Brunnbauer, U., \& Taylor, K. (2004). Creating a ‘socialist way of life’: Family and reproduction policies in Bulgaria, 1944-1989. Continuity and Change, 19(2), 283-312.

Brzozowska, Z. (2011). Przestrzenne zróżnicowanie urodzeń pozamałżeńskich w Polsce w latach 2002-2010 [Spatial differentiation of non-marital births in Poland, 2002-2010]. Studia Demograficzne, 2(160), 59-84.

Buch, T., Hamann, S., Niebuhr, A., \& Rossen, A. (2014). How to woo the smart ones? Evaluating the determinants that particularly attract highly qualified people to cities. Hamburg. Hamburg Institute of International Economics. HWWI Research Paper 159.

Burgess, E. W. (1925). The growth of the city: An introduction to a research project. In R. E. Park, E. W. Burgess, \& R. D. McKenzie (Eds.) The city: Suggestions for investigation of human behavior in the urban environment (pp. 47-62). Chicago: University of Chicago Press.

Cleveland, W. S. (1979). Robust locally weighted regression and smoothing scatterplots. Journal American Statistical Association, 74(368), 829-836.

Cutright, P. (1971). Illegitimacy: myths, causes and cures. Family Planning Perspectives, 3(1), 25-48. 
Decroly, J. M., \& Grasland, C. (1993). Boundaries, political systems and fertility in Europe. Population: An English Selection, 5, 101-119.

Edge, P. G. (1928). Vital registration in Europe: The development of official statistics and some differences in practice. Journal of the Royal Statistical Society, 91(3), 346-393.

Esping-Andersen, G. (1990). The three worlds of welfare capitalism. Princeton. Princeton University Press.

Evans, G., \& Northmore-Ball, K. (2012). The limits of secularization? The resurgence of orthodoxy in post-Soviet Russia. Journal for the Scientific Study of Religion, 51(4), 795808.

Fotheringham, A. S., Brunsdon, C., \& Charlton, M. (2003). Geographically Weighted Regression: The analysis of spatially varying relationships. Chichester: John Wiley \& Sons.

Goldhaber, M. D. (2007). A people's history of the European Court of Human Rights. New Brunswick: Rutgers University Press.

Goldstein, J. R., \& Kreyenfeld, M. (2011). Has East Germany overtaken West Germany? Recent trends in order-specific fertility. Population and Development Review, 37(3), 453-472.

Gollini, I., Lu, B., Charlton, M., Brunsdon, C., \& Harris, P. (2014). GWmodel: An R package for exploring spatial heterogeneity using geographically weighted models. Journal of Statistical Software, 63(17), 1-50.

González-Bailón, S., \& Murphy, T. E. (2013). The effects of social interactions on fertility decline in nineteenth-century France: An agent-based simulation experiment. Population Studies, 67(2), 135-155.

Goodchild, M. F., \& Lam, N. S.-N. (1980). Areal interpolation: A variant of the traditional spatial problem. Geo-Processing, 1, 297-312.

Hägerstrand, T. (1965). A Monte Carlo approach to diffusion. European Journal of Sociology, 6(1), 43-67.

Hajnal, J. (1965). European marriage patterns in perspective. In D. V. Glass, \& D. E. C. Eversley (Eds.), Population in history: Essays in historical demography (pp. 101-143). London: Edward Arnold.

Kaufmann, E., Goujon, A., \& Skirbekk, V. (2012). The end of secularization in Europe? A socio-demographic perspective. Sociology of Religion, 73(1), 69-91.

Khera, S. (1981). Illegitimacy and mode of land inheritance among Austrian peasants. Ethnology, 20(4), 307-323.

Kiernan, K. (2004). Unmarried cohabitation and parenthood in Britain and Europe. Law \& Policy, 26(1), 33-55.

Klüsener, S., \& Goldstein, J. R. (2014). A long-standing demographic East-West divide in Germany. Population, Space and Place [Online First]. 
Klüsener S., Perelli-Harris, B., \& Sánchez Gassen, N. (2013). Spatial aspects of the rise of nonmarital fertility across Europe since 1960: The role of states and regions in shaping patterns of change. European Journal of Population, 29(2), 137-165.

Klüsener, S., Devos, I., Ekamper, P., Gregory, I. N., Gruber, S., Martí-Henneberg, J., van Poppel, F., da Silveira, L. E., \& Solli, A. (2014). Spatial inequalities in infant survival at an early stage of the longevity revolution: A pan-European view across 5000+ regions and localities in 1910. Demographic Research, 30(68), 1849-1864.

Knijn, T., Martin, C., \& Millar, J. (2007). Activation as a common framework for social policies towards lone parents. Social Policy \& Administration, 41(6), 638-652.

Knodel J. (1967). Law, marriage and illegitimacy in nineteenth-century Germany. Population Studies, 20(3), 279-294.

Kok, J. (2009). Family systems as frameworks for understanding variation in extra-marital births, Europe 1900-2000. Romanian Journal of Population Studies, 3(S), 13-38.

Kolbe, W. (2002). Elternschaft im Wohlfahrtsstaat: Schweden und die Bundesrepublik im Vergleich 1945-2000 [Parenthood and the welfare state: A comparison of Sweden and the Federal Republic 1945-2000]. Frankfurt am Main: Campus-Verlag.

Kulu, H. (2013). Why do fertility levels vary between urban and rural areas? Regional Studies, 47(6), 895-912.

Kytir, J. (1992). Unehelich, vorehelich, ehelich - Familiengründung im Wandel: Eine empirische Analyse der Erstgeburten österreichischer Frauen 1950 bis 1990 [Out of wedlock, pre-marital, marital - family formation in transition: An empirical analysis of first births among Austrian women 1950-1990]. Demographische Informationen, 1990-1991, 29-40.

Lappegård T., Klüsener, S., \& Vignoli D. (2014). Social norms, economic conditions and spatial variation of childbearing within cohabitation across Europe. Rostock: Max Planck Institute for Demographic Research. MPIDR Working Paper WP-2014-002.

Laslett, P. (1980). Introduction: Comparing illegitimacy over time and between cultures. In P. Laslett, K. Oosterveen, \& R. M. Smith (Eds.), Bastardy and its comparative history. Studies in the history of illegitimacy and marital nonconformism in Britain, France, Germany, Sweden, North America, Jamaica and Japan (pp. 1-70). Cambridge, Ma.: Harvard University Press.

Le Goff, J.-M., \& Ryser, V.-A. (2010). The meaning of marriage for men during their transition to fatherhood: The Swiss context. Marriage \& Family Review, 46(1/2), 107-125.

Lesthaeghe, R. (2010). The unfolding story of the Second Demographic Transition. Population and Development Review, 36(2), 211-251.

Lesthaeghe, R., \& Neels, K. (2002). From the first to the second demographic transition: An interpretation of the spatial continuity of demographic innovation in France, Belgium and Switzerland. European Journal of Population, 18(4), 325-360. 
McLaughlin, E., \& Glendinning, C. (1994). Paying for care in Europe: Is there a feminist approach? In L. Hantrais, \& S. Mangen (Eds.), Family Policy and the Welfare of Women (pp. 52-69). Loughborough: Cross-National Research Group.

Perelli-Harris, B., \& Gerber, T. P. (2011). Nonmarital childbearing in Russia: Second demographic transition or pattern of disadvantage? Demography, 48(1), 317-342.

Perelli-Harris B., \& Sánchez Gassen, N. (2012). How similar are cohabitation and marriage? Legal approaches to cohabitation across Western Europe. Population and Development Review, 38(3), 435-467.

Perelli-Harris B., Sigle-Rushton, W., Lappegård, T., Keizer, R., Kreyenfeld, M., \& Berghammer, C. (2010). The educational gradient of childbearing within cohabitation in Europe. Population and Development Review, 36(4), 775-801.

Perelli-Harris, B., Kreyenfeld, M., Sigle-Rushton, W., Keizer, R., Lappegård, T., Jasilioniene, A., Berghammer, C., \& Di Giulio, P. (2012). Changes in union status during the transition to parenthood in eleven European countries, 1970s to early 2000s. Population Studies, 66(2), 167-182.

Reher, D. S. (1998). Family ties in Western Europe: Persistent contrasts. Population and Development Review, 24(2), 203-234.

Salles, A. (2006). The effects of family policy in the former GDR on nuptiality and births outside marriage. Population (English Edition), 61(1), 131-142.

SGF [Statistique Générale de la France]. (1907). Statistique internationale du mouvement de la population d'après les registres d'état civil: Résumé rétrospectif depuis l'origine des statistiques de l'état civil jusqu'en 1905 [International vital population statistics according to the civil registers: Retrospective summary since the origins of vital statistics until 1905]. Paris: Imprimerie national.

Shorter E. (1978). Bastardy in southern Germany: A comment. The Journal of Interdisciplinary History, 8(3), 459-469.

Stanković, B., \& Penev, G. (2012). Rađanje van braka: neki prostorni aspekt [Births outside marriage: Some spatial aspects]. Demografija [Demography], 9, 181-199.

Thünen, J. H. v. (1826). Der isolierte Staat in Beziehung auf Landwirtschaft und Nationalökonomie, oder Untersuchungen über den Einfluß, den die Getreidepreise, der Reichthum des Bodens und die Abgaben auf den Ackerbau ausüben [The isolated state in relation to agricultural and political economy, or investigations concerning the influence which grain prices, the richness of the soil, and taxes, exert upon tillage]. Hamburg: Friedrich Perthes.

Tobler W. (1970). A computer movie simulating urban growth in the Detroit region. Economic Geography, 46(2), 234-240.

Todorova, V. (2000). Family law in Bulgaria: Legal norms and social norms. International Journal of Law, Policy and the Family, 14(2), 148-181. 
Watkins, S. C. (1991). From provinces into nations: Demographic integration in Western Europe 1870-1960. Princeton: Princeton University Press.

Wray, H. E., Agoston, A., \& Hutton, J. (2014). A family resemblance? The regulation of marriage migration in Europe. European Journal of Migration and Law, 16(2), 209-247.

\subsection{Data}

\subsubsection{Demographic Data}

Council of Europe. (2005). Recent demographic developments in Europe 2004. Strasbourg: Council of Europe Publishing.

Decroly, J. M., \& Vanlaer, J. (1991). Atlas de la population européenne [Atlas of the European population]. Brussels: Editions de l’Université de Bruxelles.

Demoskop Weekly (2015). 15 novyx nezavisimyx gosudarstv. Dolja vnebračnyx roždenij (na 100 rodivšixsja), 1960-2012 [15 newly independent states. The share of non-marital births (per 100 births), 1960-2012]. Moscow: National Research University Higher School of Economics. http://www.demoscope.ru/weekly/ssp/sng_emb.php. Data downloaded 15 March 2015.

Devos, I. (2014). HISSTER-Database. Ghent: Ghent University, History Department.

Ekamper, P., \& van Poppel, F. (2008). Zuigelingensterfte per gemeente in Nederland, 18411939 [Infant mortality by municipality in the Netherlands, 1841-1939]. Bevolkingstrends, 56(1), 23-29. http://publ.nidi.nl/output/2008/bt-56-01-ekamper.pdf

\subsubsection{GIS data}

Boonstra, O. W. A. (2007). NLGis shapefiles. https://easy.dans.knaw.nl/ui/datasets/id/easydataset:44426/. Data obtained 31 March 2013.

Dansk Center for Byhistorie [Danish Centre for Urban History]. (2008). Danmarks lokaladministration 1660-2007 [The local administration of Denmark 1660-2007]. Århus: Dansk Center for Byhistorie. http://dendigitalebyport.byhistorie.dk/kommuner. Data downloaded 15 March 2015.

GADM (2012). GADM database of global administrative areas. Davis: University of California Davis. http://www.gadm.org. Data downloaded 31 March 2012

Gregory, I. N., Bennett, C., Gilham, V. L., \& Southall, H. R. (2002). The Great Britain Historical GIS project: From maps to changing human geography. The Cartographic Journal, 39(1), 37-49.

Guttormsson, L., \& Garðarsdóttir, Ó. (2002). The development of infant mortality in Iceland, 1800-1920. Hygiea Internationalis, 3(1), 151-176.

Historical Database of Local Statistics [Lokstat]. (2014). Belgian Historical GIS (supervised by Vanhaute, E., \& Vrielinck, S.). Ghent: Ghent University, History Department.

MPIDR [Max Planck Institute for Demographic Research]. (2014a). MPIDR Population History GIS Collection. Rostock: MPIDR. http://censusmosaic.org/web/data/historicalgis-files. Data downloaded 31 March 2014. 
MPIDR [Max Planck Institute for Demographic Research]. (2014b). MPIDR Population History GIS Collection - Austro-Hungarian Empire 1910 (based on a file by H. Rumpler, \& M. Seger (Eds.) (2010). Die Habsburgermonarchie 1848-1918, Band IX, Soziale Strukturen, 2. Teilband [The Habsburg monarchy 1848-1918, Volume IX, Social structures, 2nd subband]. Wien: Verlag der Österreichischen Akademie der Wissenschaften). Rostock: MPIDR. http://censusmosaic.org/web/data/historical-gis-files. Data downloaded 31 March 2014.

MPIDR [Max Planck Institute for Demographic Research]. (2014c). MPIDR Population History GIS Collection - Serbia 1865-1895 (based on files by Gruber, S.). Rostock:

MPIDR. http://censusmosaic.org/web/data/historical-gis-files. Data downloaded 31 March 2014.

Norwegian Social Science Data Services [NSD]. (2013). Norwegian Historical GIS. Bergen: NSD.

Riksarkivet (2013). Historical GIS of Sweden. Stockholm: Riksarkivet.

da Silveira, L. E., Alves, D., Lima, N. M., Alcântara, A., \& Puig, J. (2011). Population and railways in Portugal, 1801-1930. Journal of Interdisciplinary History, 42(1), 29-52. 


\section{Appendix 1: Administrative boundaries 1910}

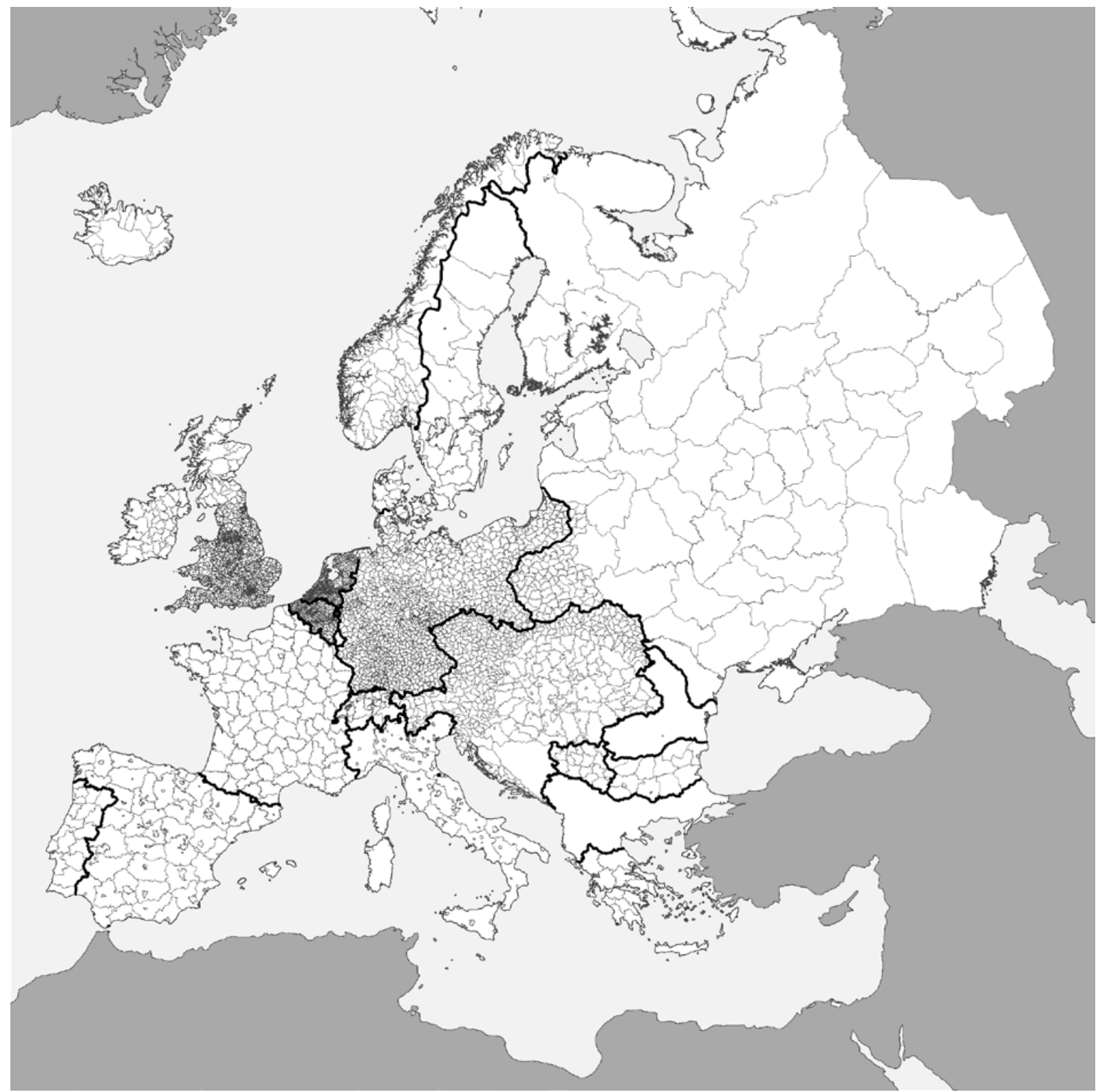

Base Map: MPIDR (2014a-c), partly based on EuroGeographics for the administrative boundaries; National Historical GIS projects (see also section 6.2.2 of references for details) 


\section{Appendix 2: Administrative boundaries 2007}

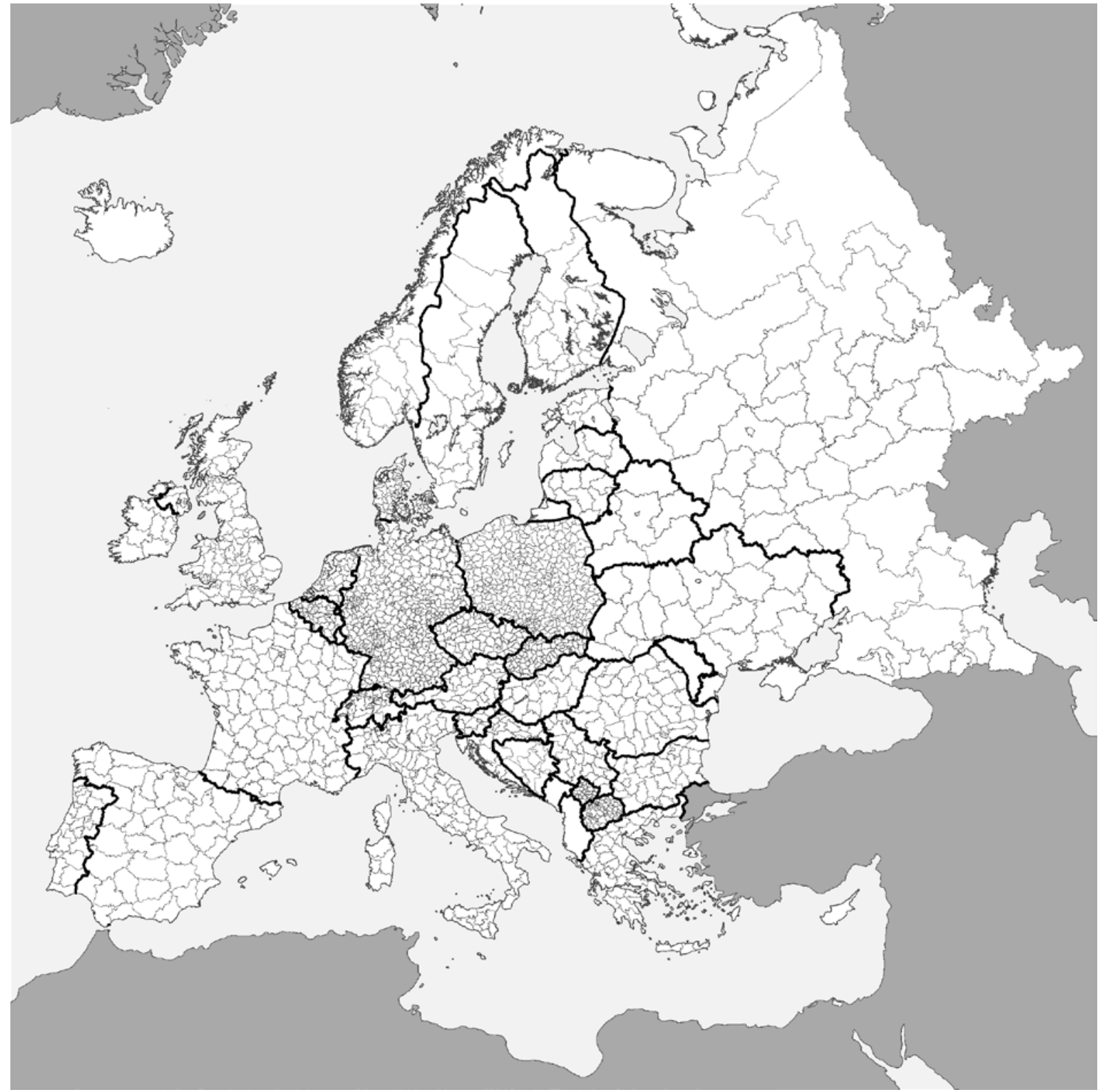

Base Map: MPIDR (2014a), partly based on EuroGeographics for the administrative boundaries; GADM (2012) 


\section{Appendix 3: Time-constant boundaries 1910-2007}

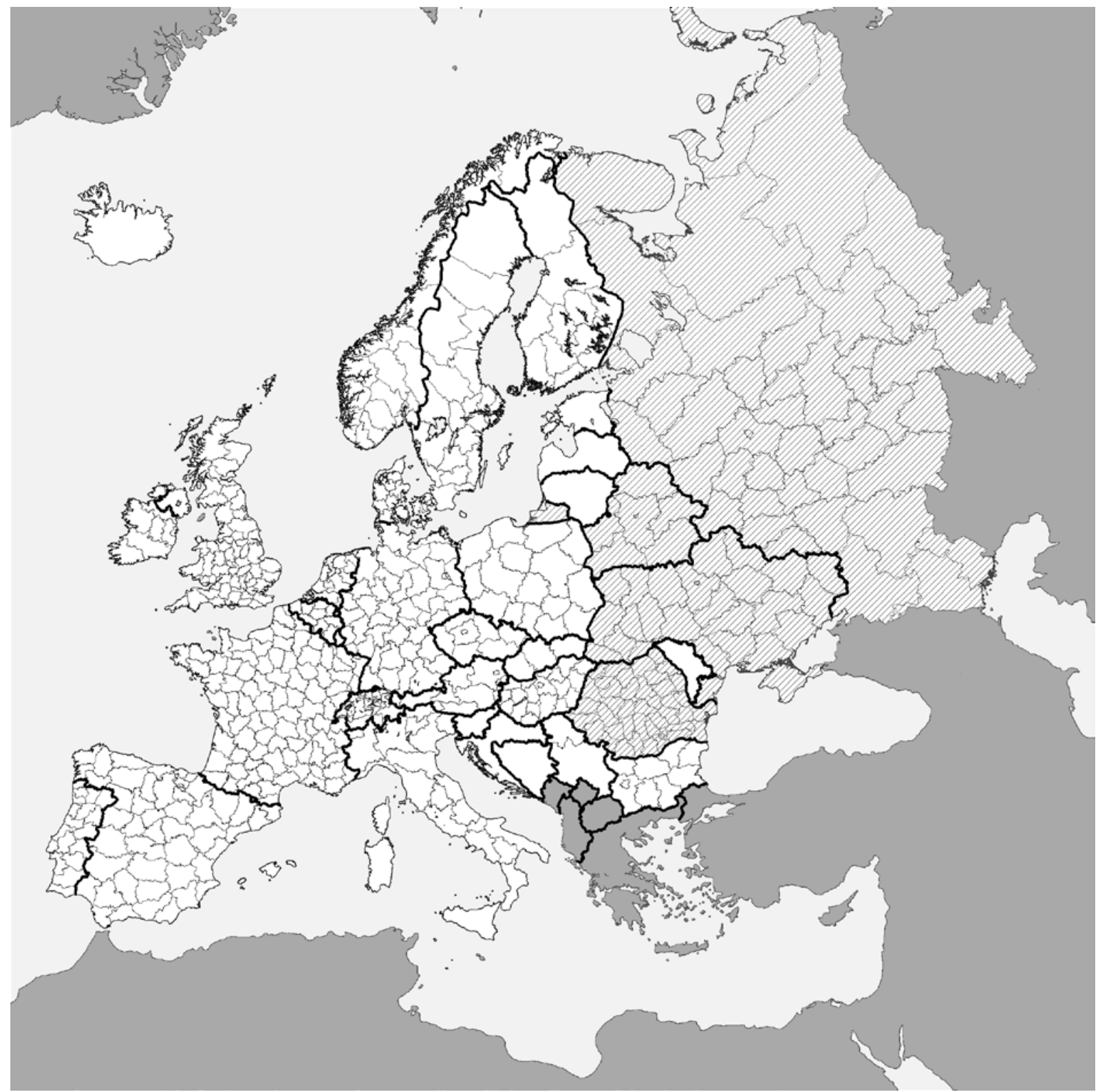

Note: The reduced sample used in the correlation analysis excludes the regions that are highlighted with shadowlines.

Base Map: MPIDR (2014a-c), partly based on EuroGeographics for the administrative boundaries 